\title{
The potential impact of a cataract surgery programme on the care of orphans and vulnerable children in Swaziland
}

\author{
J Pons, W Mapham, B Newsome, L Myer, R Anderson, P Courtright, C Cook
}

We aimed to evaluate the potential impact of a cataract surgery programme at the Good Shepherd Hospital, Siteki, Swaziland, on the care of orphans and vulnerable children in Swaziland. We studied consecutive patients aged 50 years and older undergoing surgery for age-related cataract who reported having children living in their household. Of 131 subjects recruited, 65 (49.6\%) were the primary caregivers for the child(ren) in their household. Visual acuities measured 2 weeks after surgery significantly improved. Four weeks after surgery, there was a sizable increase in the proportions of subjects who were able to undertake self-care activities, attend to activities of daily living, undertake income-generating activities and care for children. Cataract surgery on elderly visually impaired patients has the potential to impact positively on the care of orphans and vulnerable children.

S Afr Med J 2012;102:140-141
Cataract is the leading cause of blindness in Swaziland, as elsewhere in Africa. Although Swaziland has no published studies, it is likely to be similar to Malawi and Tanzania, where rates of bilateral blindness are $3.3 \%$ and $2.4 \%$, with cataracts contributing $48.2 \%$ and $52.4 \%$ of cases, respectively. ${ }^{1,2}$ Swaziland struggles to manage an HIV epidemic affecting 26\% of adults, the highest prevalence in the world. ${ }^{3}$ In 2007 it was estimated that 56000 Swazi children had been orphaned due to HIV. ${ }^{4}$ The United Nations Children's Fund (UNICEF) predicted that this would increase to 120000 orphaned children by 2010, representing $13 \%$ of Swaziland's population. ${ }^{5}$ Grandparents have a growing role as primary caregivers of AIDS orphans in sub-Saharan Africa, ${ }^{6-14}$ and in Swaziland elderly people are their main caregivers. ${ }^{15}$ In nearby Zimbabwe approximately $71 \%$ of grandparents older than 60 years have responsibilities for children orphaned by HIV/AIDS, ${ }^{16}$ and in neighbouring South Africa each elderly caregiver looks after an estimated average of 4.6 children. ${ }^{7}$ While it is universally agreed that the elderly are essential for mitigating the effects of the AIDS epidemic on orphaned children, their needs are rarely addressed by governmental or non-governmental organisations. ${ }^{17}$ The World Health Organization has therefore called for practical and sustainable approaches to improve the capacity of older people to provide care for their orphaned dependants.

This original research is published by three generations of UCT graduates. Dr Cook trained Dr Pons in ophthalmology and Dr Pons trained Dr Mapham in ophthalmology.

Good Shepherd Hospital, Siteki, Swaziland

J Pons, MB ChB, Dip Ophthal (SA), Dip Anaesth (SA)

W Mapham, MB ChB

B Newsome, $\mathrm{BA}, \mathrm{PhD}$

R Anderson, Medical Student, Edinburgh

School of Public Health and Family Medicine and Department of Ophthalmology, University of Cape Town

L Myer, BA, MB ChB, MA, MPhil, PhD

C Cook, MB ChB, MPH, FCOphthSA, FRCOphth

Kilimanjaro Centre for Community Ophthalmology, Tanzania P Courtright, DrPH
Cataract surgery can quickly and economically restore the ability of the elderly blind person to resume active incomegenerating activities and to care for dependants more effectively, yet only anecdotal reports highlight these benefits. We therefore evaluated the potential impact of a cataract surgery programme on the care of orphans and vulnerable children in Swaziland.

\section{Methods}

Swaziland has a population of 1370424 people, of whom 3.6\% are aged 65 years and over. ${ }^{18}$ During this study, Good Shepherd Hospital in Siteki in the Lubombo region was responsible for $100 \%$ of Swaziland's cataract surgery.

We enrolled consenting patients aged 50 years and older undergoing cataract surgery at Good Shepherd Hospital. The questionnaire used to interview patients before their surgery, included: 'Are there children in your home whose parents have died or who have been abandoned by their parents?' Those answering in the affirmative ('elderly orphan caregivers') were included in a follow-up study to provide additional details - the age and gender of all members of the household, information on the caregiver for the preschool child(ren) in the household, and activities they could undertake with their visual impairment (selfcare, activities of daily living, child care activities and incomegenerating activities). The patients had their presenting visual acuities of both eyes recorded before their surgery and at followup after 2 weeks.

Follow-up interviews were conducted on a selected sample of the patients living within a 1-hour drive from the hospital, in their homes after 4 weeks. They were asked to detail the activities they were now able to undertake, including questions related to child care.

Data were entered into a custom-designed Excel spreadsheet and analysed using SigmaStat 3.11 software (Systate Software Inc, Chicago, USA).

Ethical approval for the study was granted by the Good Shepherd Hospital ethics committee.

\section{Results}

Over the 8-month period 131 patients aged 50 and above were enrolled, comprising 39 men and 92 women with mean ages of 70.5 years and 69.2 years, respectively; 65 (49.6\%) reported being the primary caregiver for at least one child. Follow-up interviews were conducted with 37 patients at their homes after 4 weeks. Analysis of variance and Student's $t$-test evaluated the statistical significance of 
pre- and postoperative visual acuities and activities associated with daily child care.

Measured visual acuities significantly improved 2 weeks after surgery $(p<0.001)$ (Table 1$)$. Data represent the visual acuities of the patients' better eyes pre- and postoperatively to address the patients' overall increased abilities after surgery.

There were sizeable improvements in reported activities following surgery (Table 2).

\section{Discussion}

Swaziland has the highest documented prevalence of HIV in the world, resulting in a large number of orphans whose grandparents provide care for them. In this study, half the subjects reported being the primary caregiver for the child(ren) living in their homes, despite being visually impaired from their cataract. Visual acuities and the range of activities they were able to perform, including child care activities and income-generating activities, significantly improved following surgery.

Table 1. Pre-operative and postoperative visual acuities

\begin{tabular}{lllll}
\hline & \multicolumn{2}{c}{$\begin{array}{l}\text { Pre-operative } \\
\text { visual acuity }\end{array}$} & \multicolumn{2}{l}{$\begin{array}{l}\text { Postoperative } \\
\text { visual acuity }\end{array}$} \\
& $N$ & $\%$ & $N$ & $\%$ \\
\hline Normal $(6 / 6-6 / 18)$ & 42 & 32.1 & 86 & 65.6 \\
Visual impairment $(6 / 24-6 / 60)$ & 47 & 35.9 & 44 & 33.6 \\
Severe visual impairment & 11 & 8.4 & 1 & 0.8 \\
$(5 / 60-3 / 60)$ & & & & \\
Blind $(<3 / 60)$ & 31 & 23.7 & 0 & 0 \\
$\quad$ Total & 131 & 100 & 131 & 100
\end{tabular}

No correlation was present between change in visual acuity and age or patient gender.

Table 2. Reported improvements in activities of 37 patients interviewed before surgery and 4 weeks after surgery

\begin{tabular}{lll}
\hline & $N^{*}$ & $\%^{*}$ \\
\hline No improvement & 2 & 5.4 \\
Improved self-care & 20 & 54.1 \\
Improved activities of daily living & 23 & 62.2 \\
Improved direct care of children & 17 & 54.1 \\
Improved economic activities & 10 & 27.0 \\
& & \\
*Number and percentage of patients reporting an improvement; patients could report more \\
than one improvement.
\end{tabular}

This study has weaknesses. Patients are generally only able to afford a single postoperative visit, which is routinely scheduled after 2 weeks. However, 2 weeks was considered to be too soon to reasonably ask about any improvement in activities after surgery. While we would have liked to have visited all the patients in their homes to interview them after 4 weeks, for geographical, logistical and financial reasons this was not possible and only 37 patients were visited. Although it was possible to measure the visual acuities more objectively before and after surgery, the reported range of pre- and postoperative activities is more subjective.

Notwithstanding these weaknesses, cataract surgery resulted in a significant improvement in visual acuity and activities of daily living in these patients. Cataract surgery in this setting improves the income-generating capacity of affected families and the care of orphans and vulnerable children living in those families.

\section{References}

1. Kalua K, Lindfield R, Mtupanyama M, Mtumodzi D, Msiska V. Findings from a rapid assessment of avoidable blindness (RAAB) in Southern Malawi 2011. PLoS ONE 6(4): e19226. [doi:10.1371/journal. pone.0019226]

2. Habiyakire C, Kabona G, Courtright P, Lewallen S. Rapid assessment of avoidable blindness and cataract surgical services in Kilimanjaro Region, Tanzania. Ophthalmic Epidemiol 2010;17(2):90-94.

Central Statistical Office (Swaziland) and Macro International Inc (2007). Swaziland Demographic an The pdf (accessed 17 December 2011).

4. UNAIDS Repan DiV/AIDS Epidemic 2008. http://www.unaids.org/en/media/unaids/ cortert/pub/globalreport/2008/jc1510_2008globalreport_en.zip (accessed 17 December 2011)

5. Africas orphaned generation. http://www.unicef.org/publications/files/Africas_Orphaned_ Generation_Executive_Summary_Eng.pdf (accessed 17 December 2011).

6. Wangui EE. Livelihood strategies and nutritional status of grandparent caregivers of AIDS orphans in Nyando District, Kenya. Qual Health Res 2009;19(12):1702-1715.

7. Ardington C, Leibbrandt M. Orphanhood and schooling in South Africa: Trends in the vulnerability of orphans between 1993 and 2005. Economic Development and Cultural Change 2010;58(3):507-536.

. Knodel J, VanLandingham M, Saengtienchai C, Im-em W. Older people and AIDS: Quantitative evidence of the impact in Thailand. Soc Sci Med 2001;52(9):1313-1327.

9. Ntozi JPM, Nakayiwa S. AIDS in Uganda: How has the household coped with the epidemic? In: Orubuloye IO, Caldwell JC, Ntozi JPM, eds. 1999. The Continuing HIV/AIDS Epidemic in Africa: Responses and Coping Strategies. Canberra: Australia National University, 1999:155-181.

10. Reddy P James S. Mutumba Bily-Boon H, Williams E, Khan H. Pilot con, Reddy, Janes, Mutumba Bilay-Boon H, Williams E, Khan H. Pilot community based intervention to address the needs of elderly caregivers in the Eastern Cape Province, South Africa. Horizon
Research Summary 2009. Washington, DC: Population Council, 2009.

AIDS pandemic in sub-Saharan Africa. J Cross Cult Gerontol 2008;23(2):131-14

2. Freeman M, Nkomo N. Guardianship of orphans and vulnerable children. A survey of current and prospective South African caregivers. AIDS Care 2006;18(4):302-310.

3. Appleton J. 'At my age I should be sitting under that tree': the impact of AIDS on Tanzanian lakeshore communities. Gender and Development 2000;8(2):19-27.

4. Foster G, Makufa C, Drew R, Kambeu S, Saurombe K. Supporting children in need through community-based orphan visiting programme. AIDS Care 1996;8(4):389-403.

5. Makadzange K, Dolamo BL. Care of HIV-positive orphans by elderly people in Swaziland. CME 2011;29(2):60-64.

6. Impact of AIDS on older people in Africa. World Health Organization. http://www.who.int/hiv/pub/ casestudies/pubzimaids/en/index.html (accessed 17 December 2011).

17. Swaziland: Elderly caregivers get little support. http://www.irinnews.org/report.aspx?ReportId=76423 (accessed 17 December 2011).

18. Central Intelligence Agency's World Fact Book. https://www.cia.gov/library/publications/the-worldfactbook/geos/wz.html (accessed 17 December 2011). 